\title{
Paraoxonase 1 (PON1) activity in serum, follicular fluid and seminal plasma of sheep
}

\author{
J Pradieé $^{1,2}$ | FT de Campos ${ }^{2}$ | JAA Rincon ${ }^{2}$ | LCollares $^{2}$ | K Goularte ${ }^{2}$ | \\ PAS Silveira $^{2}$ | LMC Pegoraro $^{1}$ | A Schneider ${ }^{2}$
}

${ }^{1}$ EMBRAPA Temperate

Agriculture, Experimental Station Terras

Baixas, Capão do Leão, Brasil

${ }^{2}$ Universidade Federal de Pelotas (UFPel), Pelotas, RS, Brasil

\section{Correspondence}

Augusto Schneider, Universidade Federal de Pelotas (UFPel), Pelotas, RS, Brasil.

Email: augusto.schneider@ufpel.edu.br

\section{Funding information}

Coordenação de Aperfeiçoamento de Pessoal de Nível Superior; Fundação de Amparo à Pesquisa do Estado do Rio Grande do Sul; Conselho Nacional de Desenvolvimento Científico e Tecnológico; Empresa Brasileira de Pesquisa Agropecuária

\section{Contents}

This work aimed to describe the activity of paraoxonase 1 (PON1) in serum, follicular fluid and seminal plasma of sheep. Average serum PON1 activity was $286.8 \pm 96.2 \mathrm{U} /$ $\mathrm{ml}$ in females and $237.6 \pm 18.9 \mathrm{U} / \mathrm{ml}$ in males. There was a positive correlation between PON1 activity in serum and follicular fluid in females, being twice higher in serum than in follicular fluid $(148.8 \pm 15.7 \mathrm{U} / \mathrm{ml})$. PON1 activity in males' serum was 10 -fold higher than in seminal plasma $(21.18 \pm 14.2 \mathrm{U} / \mathrm{ml})$, and there was no correlation between PON1 activity in both compartments. Finally, this work suggests that PON1 activity of in sheep is higher compared to other mammalian species, and there is an association between PON1 in serum and follicular fluid only.
The paraoxonase (PON) comprises a family of three enzymes (PON1, PON2 and PON3), from which PON1 is the most studied enzyme and synthesized primarily by the liver, where is secreted associated with high-density lipoproteins (HDL) (Ceron, Tecles, \& Tvarijonaviciute, 2014). PON1 has multifunctional roles in various biochemical pathways such as protection against oxidative damage and lipid peroxidation, contribution to innate immunity and detoxification of reactive molecules (Ceron et al., 2014).

HDL is the main lipoprotein in the follicular fluid (FF) and is transferred from serum into the follicle together with PON1 in cattle (Campos et al., 2017; Schneider, Absalon-Medina, Esposito, Correa, \& Butler, 2013). The presence of PON1 in the FF is important because it is positively associated with embryonic development due to its antioxidant properties (Rincón et al., 2016). Similarly, semen quality is attributed to many factors, including the biochemical constituents of the seminal plasma (Assumpção, Torres., Sousa, \& Ricart, 2005). The balance between antioxidants and reactive oxygen species (ROS) is responsible for most cases of male infertility, specifically defects on sperm function (Vernet, Aitken, \& Drevet, 2004). In this sense, the PON1 protein was previously detected in human and boar seminal plasma and associated with fertility responses (Barranco et al., 2015; Verit, Verit, Ciftci, Erel, \& Elik, 2009).
Our group has previously demonstrated the presence of serum PON1 activity in various species, including mouse (Garcia et al., 2016), human (Santos et al., 2016) and bovine (Krause et al., 2014; Schneider et al., 2013). Besides that, there is just one previous report of PON1 paraoxon activity in serum of sheep (Arslan, Erzengin, \& Demir, 2011), suggesting that PON1 can be used for the assessment of long-term health risks of sheep exposed to pesticides. However, we measured the PON1 arylesterase activity in the current work, which can provide the basis for comparing results between different species and also to serve as a reliable marker in order to establish reference values for sheep. Given significant PON1 implications on reproductive function and overall animal health, the aim of this work was to determine the PON1 enzyme activity in serum, follicular fluid and seminal plasma of sheep.

This study was approved by the Ethics Committee in Animal Experimentation from the Universidade Federal de Pelotas. During the experiment, sheep ( 3 males and 27 females) were maintained under pasture conditions $\left(31^{\circ} 45^{\prime} \mathrm{S}\right.$ latitude and $52^{\circ} 21^{\prime} \mathrm{W}$ longitude) and had free access to water. Twenty-seven females were synchronized using medroxyprogesterone acetate-impregnated sponges for 14 days. Eight females were sent to a slaughterhouse 2 days after sponge removal, and nineteen were artificially inseminated using the transcervical technique. Pregnancy diagnosis was performed 30 days after 
artificial insemination (Al) by ultrasonography. Blood samples were collected at the moment of $\mathrm{Al}(n=19)$ or one hour before sacrifice for females in the slaughterhouse $(n=8)$. Additionally, the pair of ovaries ( $n=8$ ) was collected, the largest follicle was aspirated with a syringe and the follicular fluid was recovered for analysis.

Semen and serum samples were also collected from three males once a week during 10 weeks. Semen samples were collected with an artificial vagina. Part of the semen sample was centrifuged (for $10 \mathrm{~min}$ at $1,000 \times \mathrm{g}$ ) for seminal plasma recovery, and part was used for semen analysis: morphology, membrane and acrosome integrity, concentration and motility, with a computer-assisted semen analysis (CASA) system. Blood samples were collected just before semen collection.

PON1 arylesterase activity was quantified by the rate of phenol extinction at $270 \mathrm{~nm}$ in samples of serum and follicular fluid from the females and also in serum and seminal plasma from the males as previously described (Campos et al., 2017). Three samples of seminal plasma were not analysed due low volume obtained.

Statistical analysis was performed using GraphPad Prism 5 (GraphPad Software Inc., La Jolla, CA, USA). Data were analysed by comparing PON1 activity in the serum of pregnant and not pregnant ewes by $t$ test, and correlating PON1 activity in serum and follicular fluid of ewes. Seminal plasma and serum PON1 activity were also correlated, and PON1 activity in serum and seminal plasma were correlated with the evaluated semen parameters, using a linear and quadratic regression model in SAS (SAS University Edition, SAS, Cary, NC, USA).

To our knowledge, this is the first study to report PON1 arylesterase activity in sheep serum, follicular fluid and seminal plasma. Average serum PON1 activity was $286.8 \pm 96.2 \mathrm{U} / \mathrm{ml}$ in females and $237.6 \pm 18.9 \mathrm{U} / \mathrm{ml}$ in males (Figure $1 \mathrm{~A}$ ). When we compare this activity with previous observations from our group using the same technique for PON1 measurements (arylesterase activity by the phenol extinction coefficient) in humans ( 110 U/ml; Santos et al., 2016), mice ( 115 U/ml; Garcia et al., 2016) and cows ( 130 U/ml; Campos et al., 2017; Krause et al., 2014), we can notice that PON1 activity in sheep is on average two to three times higher. We are not aware of previous reports of PON1 arylesterase activity at these levels in other species. Results of our previous assays also corroborate with results from others regarding serum PON1 activity in humans, mice and cows (Ceron et al., 2014). There was no difference in serum PON1 activity between ewes that later became pregnant $(310.5 \pm 14.2 \mathrm{U} / \mathrm{ml})$ or not (348.1 $\pm 14.2 \mathrm{U} / \mathrm{ml})$, indicating no association between serum PON1 levels and probability of pregnancy.

In females, there was a positive correlation $\left(r^{2}=.96 ; p=.0001\right)$ between PON1 activity in serum and follicular fluid (Figure 1B), being twice higher in serum than in follicular fluid $(148.8 \pm 15.7 \mathrm{U} / \mathrm{ml})$. This observation is in agreement with the previously observed in cows (Campos et al., 2017; Schneider et al., 2013) and in humans (Kim, Bloom, Fujimoto, \& Browne, 2017), indicating that most PON1 in follicular fluid also originates from serum bound to HDL in sheep, as expected.

In males, PON1 activity was ten times higher in serum than in seminal plasma $(21.18 \pm 14.2 \mathrm{U} / \mathrm{ml})$, and there was no correlation between PON1 activity in both compartments (Figure 1C; $r^{2}=.009 ; p=.65$ ). Only semen concentration was correlated with PON1 activity in seminal plasma $\left(r^{2}=.16 ; p=.049\right)$. This finding is in agreement with previous observations in humans (Verit et al., 2009) and boars (Barranco et al., 2015), in which PON1 activity had a positive correlation with semen concentration. Additionally, previous findings in normozoospermic men revealed a strong association between PON2 311S allele and high sperm concentration (Lazaros et al., 2011). In the same study, the PON1 55L and PON1 192Q alleles were associated with higher sperm motility, supporting the influence of PON1 on human spermatogenesis and sperm quality. However, in our experiment there was no correlation for other analysed parameters with serum or seminal plasma PON1 (data not shown).

In sum, the current work suggests that PON1 activity of in sheep is higher compared to previous descriptions in other mammalian species. PON1 activity in serum was correlated with follicular fluid activity in females, but not with seminal plasma in males. Despite that, seminal plasma PON1 activity was associated with sperm concentration.

\section{ACKNOWLEDGEMENTS}

The authors acknowledge EMBRAPA, CAPES, CNPq and FAPERGS for financing the study.
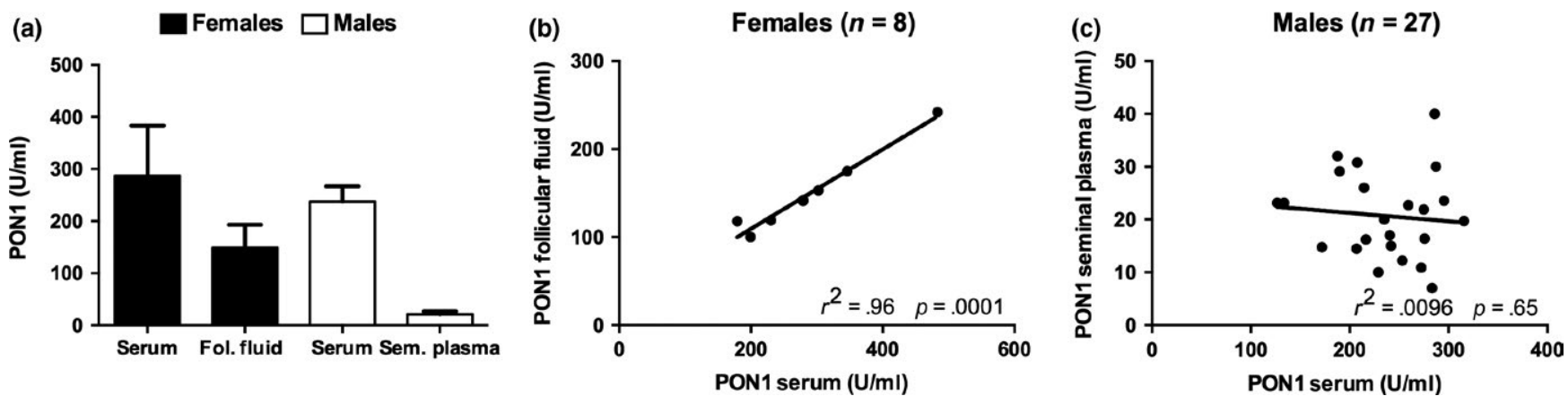

FIGURE 1 Paraoxonase activity (PON1; U/ml) in serum, follicular fluid and seminal plasma of sheep (a); correlation between PON1 activity in follicular fluid and serum of females (b) and between seminal plasma and serum of males (c) 


\section{CONFLICT OF INTEREST}

None of the authors of this study has a financial or personal relationship with other people or organizations that could inappropriately influence or bias the content of the manuscript.

\section{AUTHOR CONTRIBUTIONS}

JP contributed to study design, data analysis, experimental work and writing the manuscript. FTC, JAAR, LC, KG and PASS contributed to experimental work. LMCP and AS contributed to study design, data analysis and revision of the manuscript.

\section{REFERENCES}

Arslan, M., Erzengin, M., \& Demir, D. (2011). Comparison of serum paraoxonase 1 (PON1) activities among different sheep breeds in Turkey. Journal of Animal and Veterinary Advances, 10(4), 489-494.

Assumpção, T. I., Torres., R. A. A. Jr, Sousa, M. V., \& Ricart, C. A. O. (2005). Correlation between fertility and levels of protein, sugar and free amino acids in seminal plasma of Nelore bulls. Arquivo Brasileiro de Medicina Veterinária e Zootecnia, 57, 123-129.

Barranco, I., Roca, J., Tvarijonaviciute, A., Ruber, M., Vicente-Carrillo, A., Atikuzzaman, M., ... Rodriguez-Martinez, H. (2015). Measurement of activity and concentration of paraoxonase 1 (PON-1) in seminal plasma and identification of PON-2 in the sperm of boar ejaculates. Molecular Reproduction \& Development, 82, 58-65.

Campos, F. T., Rincon, J. A. A., Acosta, D. A. V., Silveira, P. A. S., Pradiee, J., Corrêa, M. N., ... Schneider, A. (2017). The acute effect of intravenous lipopolysaccharide injection on serum and intrafollicular HDL components and gene expression in granulosa cells of the bovine dominant follicle. Theriogenology, 89, 244-249.

Ceron, J. J., Tecles, F., \& Tvarijonaviciute, A. (2014). Serum paraoxonase 1 (PON1) measurement: An update. BMC Veterinary Research, 10, 74.

Garcia, D. N., Prietsch, L. A., Rincón, J. A. A., Moreira, I. L., Valle, S. C., Barros, C. C., ... Corrêa, M. N. (2016). Differential effects of a high-fat diet on serum lipid parameters andovarian gene expression in young and aged female mice. Zygote, 24, 676-683.

Kim, K., Bloom, M. S., Fujimoto, V. Y., \& Browne, R. W. (2017). Associations between PON1 enzyme activities in human ovarian follicular fluid and serum specimens. PLoS ONE, 12(2), e0172193.

Krause, A. R. T., Pfeifer, F. M. L., Montagner, P., Weschenfelder, M. M., Schwegler, E., Lima, M. E., ... Schneider, A. (2014). Associations between resumption of postpartum ovarian activity, uterine health and concentrations of metabolites and acute phase proteins during the transition period in Holstein cows. Animal Reproduction Science, 145, 8-14.

Lazaros, A. L., Xita, N. V., Hatzi, E. G., Kaponis, A. I., Stefos, T. J., Plachouras, N. I., ... Georgiou, I. A. (2011). Association of paraoxonase gene polymorphisms with sperm parameters. Journal of Andrology, 32, 394-401.

Rincón, J. A. A., Madeira, E. M., Campos, F. T., Mion, B., Silva, J. F., AbsalónMedina, V. A., ... Schneider, A. (2016). Exogenous paraoxonase-1 during oocyte maturation improves bovine embryo development in vitro. Reproduction in Domestic Animals, 51, 827-830.

Santos, F. G., Becker, M. K., Corrêa, V. S., Garcia, D. N., Vale, S. C., CrespoRibeiro, J. A., ... Schneider, A. (2016). The effect of the paraoxonase 1 (PON1) T(-107)C polymorphism on serum PON1 activity in women is dependent on fatty acid intake. Nutrition Research, 36, 9-15.

Schneider, A., Absalon-Medina, V. A., Esposito, G., Correa, M. N., \& Butler, W. R. (2013). Paraoxonase (PON) 1, 2 and 3 expression in granulosa cells and PON1 activity in follicular fluid of dairy cows. Reproduction in Domestic Animals, 48, 989-994.

Verit, F. F., Verit, A., Ciftci, H., Erel, O., \& Elik, H. C. (2009). Paraoxonase-1 activity in subfertile men and relationship to sperm parameters. Journal of Andrology, 30, 183-189.

Vernet, P., Aitken, R. J., \& Drevet, J. R. (2004). Antioxidant strategies in the epididymis. Molecular and Cellular Endocrinology, 216, 31-39.

How to cite this article: Pradieé J, Campos FT, Rincon JAA, et al. Paraoxonase 1 (PON1) activity in serum, follicular fluid and seminal plasma of sheep. Reprod Dom Anim. 2017;00:1-3. https://doi.org/10.1111/rda.13015 